\title{
Interaural Comparison of Audiotory Brainstem Response in Unilateral Tinnitus Patients
}

\author{
Min Su Kang, Ji Eun Choi, Min Young Lee, and Jae Yun Jung \\ Department of Otorhinolaryngology-Head and Neck Surgery, Dankook University College of Medicine, Cheonan, Korea
}

\author{
일측 이명 환자에서의 청성뇌간반응 결과의 양이비교 분석 \\ 강민수 · 최지은 · 이민영 · 정재윤 \\ 단국대학교 의과대학 이비인후-두경부외과학교실
}

\author{
Received May 17, 2017 \\ Revised June 28, 2017 \\ Accepted July 12, 2017 \\ Address for correspondence \\ Jae Yun Jung, MD \\ Department of Otorhinolaryngology- \\ Head and Neck Surgery, \\ Dankook University \\ College of Medicine, \\ 201 Manghyang-ro, Dongnam-gu, \\ Cheonan 31116, Korea \\ Tel $+82-41-550-3973$ \\ Fax $+82-41-556-1090$ \\ E-mail jjkingy2k@gmail.com
}

Background and Objectives Tinnitus is a common symptom in otolaryngology. While there have been some animal studies of unique findings in auditory brainstem response (ABR), there have not been much reports related to ABR waves and tinnitus. Recently, some human studies have been reported on the specific characteristics of ABR wave in tinnitus patients. In this study, we compared waveform characteristics of the tinnitus ear with those of non-tinnitus ear in unilateral tinnitus patients.

Subjects and Method A retrospective review was carried out for 101 patients, who had been enrolled from January 2011 to April 2016 for the treatment of unilateral tinnitus. ABR parameters between the tinnitus ear and the normal ear were compared. The entire population was divided into two groups, a right tinnitus group and a left tinnitus group, and each group was compared interaurally.

Results Latency delay and amplitude differences were observed in the ipsilesional wave III, but the ratio differences were not significant. The right tinnitus patient group showed an increased amplitude but no latency delay in the wave III and V. The left tinnitus patient group showed a latency delay in the wave I, III, and V and a decreased amplitude difference in the wave III.

Conclusion When the ABR waveform of unilateral tinnitus patients were compared interaurally, different ABR characteristics were observed between the right and left tinnitus. This may raise the possibility of a different pathophysiologic mechanism between the right and left ear. Korean J Otorhinolaryngol-Head Neck Surg 2018;61(3):127-32

Key Words ABR Amplitude ratio - Unilateral tinnitus.

\section{서 론}

이명(tinnitus)은 외부에서의 소리 자극이 없는 상태에서 청각 신호를 인식하는 증상으로 대부분은 다른 사람이 들을 수 없는 주관적 이명이다. 이명의 병태생리는 아직 확실히 규 명된 바가 없으나, 국내에서 시행된 국민건강영양조사에 따르 면 12 세 이상의 인구 $19.7 \%$ 에서 이명을 경험한 적이 있고, 이 중

This is an Open Access article distributed under the terms of the Creative Commons Attribution Non-Commercial License (http://creativecommons.org/licenses/by-nc/4.0) which permits unrestricted non-commercial use, distribution, and reproduction in any medium, provided the original work is properly cited.
$29.3 \%$ 는 생활에 불편할 정도의 이명을 가지고 있다고 보고하 였다. ${ }^{1,2)}$ 임상적으로 의미 있는 이명을 가진 환자 중 $26.8 \%$ 가 청력소실을 가지고 있으며, ${ }^{1)}$ 주로 $4,6,8 \mathrm{kHz}$ 의 고주파 영역의 청력소실과 관련이 있다. ${ }^{3)}$ 또한 청력소실이 있는 환자의 $42.8 \%$ 에서 이명을 호소하는 것으로 알려져 있다.")

이명의 기원이 내이 유래의 말초성 질환인지, 뇌 중추신경 계를 포함한 중추성 질환인지에 대한 구분은 명확하지 않으 나, 이명의 병태생리를 설명하는 세포 기전의 기본적 이론에 의하면 청력소실에 의해 청신경 활성이 감소하여 중추 청각신 경계의 억제성 신호가 차단되면, 중추 청각신경계의 신경 과활 
성이 유발되어 이명이 발생한다고 설명할 수 있다. ${ }^{5,6)}$ 하지만 일 부 환자들은 이명에도 불구하고 순음청력검사상 정상청력을 보여 환자 상담 시 이명의 병태생리를 이해시키는 데에 어려움 이 따른다. ${ }^{7,8)}$

과거 동물 실험을 통해 이명이 있는 경우 청성뇌간반응(auditory brainstem response, ABR)의 이상 소견이 확인되었고, ${ }^{9}$ 최근 정상청력을 가진 이명 환자에서 청성뇌간반응의 $\mathrm{V}$ 파 잠 복기(wave V latency) 증가, V파/I파 진폭비(wave V/I amplitude ratio)의 증가 등이 보고되었다. ${ }^{2)}$ 하지만 연구 대상자의 수가 크지 않아 추가 연구가 필요하다.

본 연구에서는 충분한 연구 대상자의 수를 확보하기 위해 대 조군을 따로 설정하지 아니하고, 편측 이명을 호소하는 환자들 만을 대상으로 병변 측과 건 측의 청성뇌간반응을 비교하였 다. 즉, 일측성 이명 환자에서 병변 측과 건 측 귀의 청성뇌간 반응상 잠복기(latency), 진폭(amplitude), 진폭비(amplitude ratio) 등을 비교하였고, 이명의 방향(우측/좌측)에 따른 청성 뇌간반응과 정상청력에서의 청성뇌간반응을 비교하였다.

\section{대상 및 방법}

\section{대 상}

2011년 1월부터 2016년 4월까지 일측 비박동성 이명을 주 소로 단국대학교병원 이비인후과를 내원한 환자의 의무기록 을 후향적으로 검토하였다. 이 중 다음의 선정기준 및 제외기 준을 모두 만족시키는 101명을 대상으로 분석하였다. 선정기 준은 1) 초진 시 순음청력검사, 이명도검사, 청성뇌간반응검 사를 모두 한 달 이내 시행한 경우, 2) $1,2,4 \mathrm{kHz}$ 에서 골도-기 도 청력 간 차이가 $10 \mathrm{~dB}$ 이하인 경우, 3) $1,2,4 \mathrm{kHz}$ 에서 좌 우의 청력 차이가 $10 \mathrm{~dB}$ 이하인 경우이며, 제외기준은 청신경 종양의 감별을 위해, 청성뇌간반응검사상 $\mathrm{V}$ 파 이간 잠복기 차이(interaural wave V latency difference)가 $0.2 \mathrm{~ms}$ 를 초과 하는 경우로 하였다. ${ }^{10)}$

\section{청성뇌간반응(Auditory brainstem response) 검사방법 및 측정지표 ${ }^{11}$}

청성뇌간유발 반응검사는 방음실에서 실시되었으며, Auditory evoked potential system, navigation Pro, Version 7.0.0 (Bio-logic ${ }^{\circledR}$ System Corp., Mundelein, IL, USA)를 이용해 검사가 진행되었다. 피검자는 앙와위로 하고, 활동전극을 전 두부에, 기준전극은 동측 이개에, 점지전극은 반대측 이개에 각각 부착하였다. 자극음은 초당 13.3 회의 반복으로 교대상 클릭(click)음을 삽입형 이어폰(Bio-logic Insert Earphones 580-SINSER, natus, San Carlos, CA, USA)을 통해 $90 \mathrm{dBn}$
$\mathrm{HL}$ 의 강도로 주었고, 총 자극음의 횟수는 1000 회로 하였다. 모든 전기저항은 $5 \mathrm{k} \Omega$ 이하로 하되 항상 $3 \mathrm{k} \Omega$ 이하를 유지 하였다. 분석한 측정지표는 다음과 같다. 1) I파, III파, V파의 잠복기 및 진폭, 2) I-III파 간 및 III-V파 간 잠복기(wave IIII, wave III-V interpeak latency), 3) III파/I파 및 V파/I파 진폭비(wave III/I, wave V/I amplitude ratio). 본 연구에서 의 진폭은 peak to trough 방법으로 측정하였다.

\section{이명도검사(Tinnitogram) $)^{12)}$}

이명도검사는 이명을 주소로 내원한 초진 시 시행하였다. 검 사항목으로 이명주파수검사(tinnitus pitch matching), 강도검 사(tinnitus loudness matching)를 실시한 후, 최소 차폐수준 (minimal masking level)을 측정하였다. 그 외 환자에 따라 최소 차폐수준상 $10 \mathrm{~dB}$ 의 순음을 1 분간 부하한 결과를 측정 하여 잔류억제(residual inhibition)검사를 sensation level(dB) 로 기록하였다.

\section{통계 분석방법}

통계 분석은 SPSS ver. 18.0 for Windows(PASW Statistics, SPSS Inc., Chicago, IL, USA)를 사용하였다. 이명의 방향에 따른 환자들의 인구학적 특성, 이명도검사(tinnitogram), 순음 청력검사를 비교하기 위해 Independent t-test와 chi-square test를 사용하였다. 또한 병측과 검측 사이에 순음청력 역치 를 비교하기 위해 paired t-test를 시행하였다

청성뇌간반응 결과를 비교하기 위해 건 측과 병 측으로 나 누어 paired t-test를 시행하였고, 분석 대상을 1) 전체 환자, 2) 좌측에만 이명이 있는 환자, 3) 우측에만 이명이 있는 환자, 4) 정상청력 $(250 \mathrm{~Hz} 8 \mathrm{kHz}$ 의 순음청력검사상 기도청력 역치 가 모두 $20 \mathrm{~dB}$ 이하)을 가진 이명 환자로 나누어 분석하였다. 모든 분석에 있어 $p$-value 0.05 이하인 경우를 의미 있는 차 이로 간주하였다.

\section{결 과}

\section{인구학적 특성 및 청각학적 특성}

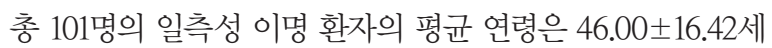
(11 82세)이며, 남자 43명, 여자 58명을 대상으로 분석하였다 (Table 1). 이 중 순음청력검사상 전 주파수에서 정상청력인

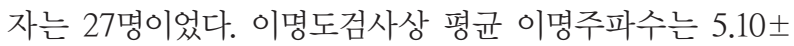

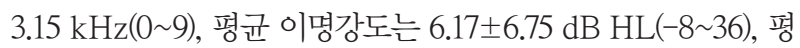
균 최소 차폐수준은 $-0.15 \pm 9.66 \mathrm{~dB} \mathrm{SL}(-12$ 33)이었다. 전체 환자 중 이명의 방향이 우측인 경우는 43 명, 좌측인 경우는 58 명이었으며, 이명 방향에 따른 성별, 나이, 정상청력의 비율, 이 
Interaural ABR Comparison in Tinnitus Patients I Kang MS, et al.

Table 1. Demographics and audiologic feature

\begin{tabular}{|c|c|c|c|c|}
\hline & Total $(n=101)$ & Rt. tinnitus $(n=43)$ & Lt. tinnitus $(n=58)$ & p-value \\
\hline \multicolumn{5}{|l|}{ Demographics } \\
\hline$M: F$ ratio & 0.74 & 0.59 & 0.87 & 0.417 \\
\hline Age (year) & $46.00 \pm 16.42$ & $45.16 \pm 16.29$ & $46.62 \pm 16.62$ & 0.661 \\
\hline Normal hearing & $27(26.70 \%)$ & $15(34.88 \%)$ & $12(20.68 \%)$ & 0.119 \\
\hline Onset (month) & $14.89 \pm 27.67$ & $18.78 \pm 36.63$ & $12.07 \pm 18.60$ & 0.233 \\
\hline \multicolumn{5}{|l|}{ Tinnitogram } \\
\hline Pitch (kHz) & $5.10 \pm 3.15$ & $5.24 \pm 3.13$ & $4.98 \pm 3.20$ & 0.711 \\
\hline Loudness (dB HL) & $6.17 \pm 6.75$ & $7.51 \pm 8.19$ & $5.05 \pm 5.09$ & 0.102 \\
\hline MML (dB SL) & $-0.15 \pm 9.66$ & $-0.90 \pm 8.31$ & $0.51 \pm 10.79$ & 0.556 \\
\hline \multicolumn{5}{|l|}{ Pure tone thresholds ( $\mathrm{dB}$ ) } \\
\hline Ipsilesional 1 kHz & & $13.72 \pm 9.51$ & $15.09 \pm 11.18$ & 0.520 \\
\hline Ipsilesional $2 \mathrm{kHz}$ & & $17.21 \pm 13.50$ & $18.62 \pm 13.37$ & 0.603 \\
\hline Ipsilesional 4 kHz & & $23.60 \pm 18.33$ & $27.16 \pm 18.80$ & 0.345 \\
\hline Contralesional $1 \mathrm{kHz}$ & & $12.79 \pm 8.68$ & $14.22 \pm 10.16$ & 0.458 \\
\hline Contralesional $2 \mathrm{kHz}$ & & $16.74 \pm 14.13$ & $17.84 \pm 13.47$ & 0.692 \\
\hline Contralesional $4 \mathrm{kHz}$ & & $23.26 \pm 19.26$ & $26.29 \pm 18.34$ & 0.423 \\
\hline
\end{tabular}

M: male, F: female, MML: minimal masking level, Rt.: right, Lt.: left

Table 2. Audiologic feature: pure tone audiometry

\begin{tabular}{|c|c|c|c|}
\hline & Ipsilesional & Contralesional & $\mathrm{p}$-value \\
\hline \multicolumn{4}{|c|}{ A) All patient } \\
\hline $1 \mathrm{kHz}$ & $14.50 \pm 10.47$ & $13.61 \pm 9.54$ & 0.026 \\
\hline $2 \mathrm{kHz}$ & $18.02 \pm 13.38$ & $17.38 \pm 13.70$ & 0.197 \\
\hline $4 \mathrm{kHz}$ & $25.64 \pm 18.59$ & $25.00 \pm 18.70$ & 0.254 \\
\hline \multicolumn{4}{|c|}{ B) Right tinnitus group } \\
\hline $1 \mathrm{kHz}$ & $13.72 \pm 9.51$ & $12.79 \pm 8.68$ & 0.146 \\
\hline $2 \mathrm{kHz}$ & $17.21 \pm 13.50$ & $16.74 \pm 14.13$ & 0.511 \\
\hline $4 \mathrm{kHz}$ & $23.60 \pm 18.33$ & $23.26 \pm 19.26$ & 0.691 \\
\hline \multicolumn{4}{|c|}{ C) Left tinnitus group } \\
\hline $1 \mathrm{kHz}$ & $15.09 \pm 11.18$ & $14.22 \pm 10.16$ & 0.096 \\
\hline $2 \mathrm{kHz}$ & $18.62 \pm 13.37$ & $17.84 \pm 13.47$ & 0.268 \\
\hline $4 \mathrm{kHz}$ & $27.16 \pm 18.80$ & $26.29 \pm 18.34$ & 0.248 \\
\hline
\end{tabular}

명 기간, 이명도검사, 순음청력검사에는 유의한 차이가 관찰되 지 않았다(Table 1).

전체 환자를 대상으로 병변 측과 건 측의 순음청력을 비교 했을 때, $1 \mathrm{kHz}$ 에서 평균 $1 \mathrm{~dB}$ 미만으로 병변 측이 건 측보 다 유의하게 역치가 낮았다 $(p=0.026)$ (Table 2A). 하지만 그 외 주파수별 $(2 \mathrm{kHz}$ 와 $4 \mathrm{kHz})$ 유의한 청력역치의 차이는 관 찰되지 않았고, 우측 이명군과 좌측 이명군에서는 모든 주파 수에서 병변 측과 건 측의 유의한 청력역치의 차이는 관찰되 지 않았다(Table 2B and C).

\section{전체 환자군의 청성뇌간반응 측정지표의 비교}

전체 환자를 대상으로 병변 측과 건 측의 청성뇌간반응을 비교하였을 때, 건 측에 비해 병변 측의 III파 잠복기가 통계
Table 3. Auditory brainstem response parameters in all patient $(n=101)$

\begin{tabular}{|c|c|c|c|c|}
\hline & Ipsilesional & Contralesional & Difference & p-value \\
\hline \multicolumn{5}{|c|}{ Latency difference (ms) } \\
\hline I & $1.44 \pm 0.12$ & $1.42 \pm 0.11$ & $0.01 \pm 0.09$ & 0.120 \\
\hline III & $3.66 \pm 0.19$ & $3.60 \pm 0.16$ & $0.05 \pm 0.14$ & 0.001 \\
\hline$\vee$ & $5.55 \pm 0.26$ & $5.53 \pm 0.25$ & $0.01 \pm 0.08$ & 0.125 \\
\hline \multicolumn{5}{|c|}{ Interpeak latency (ms) } \\
\hline$|-|||$ & $2.21 \pm 0.17$ & $2.17 \pm 0.16$ & $0.03 \pm 0.15$ & 0.014 \\
\hline$\| I I-\mathrm{V}$ & $1.89 \pm 0.18$ & $1.92 \pm 0.19$ & $-0.03 \pm 0.13$ & 0.004 \\
\hline$I-V$ & $4.10 \pm 0.25$ & $4.10 \pm 0.25$ & $0.00 \pm 0.11$ & 0.912 \\
\hline \multicolumn{5}{|c|}{ Amplitude difference (peak to trough) $(\mu \mathrm{V})$} \\
\hline I & $0.26 \pm 0.13$ & $0.26 \pm 0.15$ & $0.00 \pm 0.13$ & 0.757 \\
\hline III & $0.29 \pm 0.12$ & $0.31 \pm 0.13$ & $-0.02 \pm 0.12$ & 0.038 \\
\hline$\vee$ & $0.49 \pm 0.17$ & $0.48 \pm 0.17$ & $0.01 \pm 0.17$ & 0.512 \\
\hline III/I & $1.45 \pm 1.17$ & $1.66 \pm 1.60$ & $-0.21 \pm 1.47$ & 0.150 \\
\hline $\mathrm{V} / \mathrm{l}$ & $2.87 \pm 4.33$ & $2.77 \pm 3.02$ & $0.10 \pm 3.38$ & 0.756 \\
\hline
\end{tabular}

적으로 유의하게 지연되었다 $(p=0.001)$ (Table 3). 통계적으로 병변 측에서 I-III파 간 잠복기의 유의한 지연이 관찰되고 $(p=$ 0.014)(Table 3), III-V파 간 잠복기의 유의한 단축이 관찰되었 는데( $p=0.004$ )(Table 3 ), 이는 III파 잠복기의 지연에 기인하는 것으로 생각된다. 그 외 I파와 $\mathrm{V}$ 파의 잠복기, $\mathrm{I}-\mathrm{V}$ 파 간 잠복기 의 경우 통계적으로 유의한 차이는 없었다. 진폭의 경우 건 측 에 비해 병변 측에서 III파의 유의한 진폭의 감소가 관찰되었 으나 $(p=0.038)$ (Table 3), III파/I파 진폭비의 감소는 통계적으 로 유의하지 않았다. 그 외 I파와 $\mathrm{V}$ 파의 진폭에는 통계적인 차 이가 관찰되지 않았다. 
Table 4. Auditory brainstem response parameters in right tinnitus patient $(n=43)$

\begin{tabular}{|c|c|c|c|c|}
\hline & Ipsilesional & Contralesional & Difference & $p$-value \\
\hline \multicolumn{5}{|c|}{ Latency difference (ms) } \\
\hline I & $1.43 \pm 0.14$ & $1.44 \pm 0.12$ & $-0.01 \pm 0.08$ & 0.189 \\
\hline III & $3.62 \pm 0.17$ & $3.63 \pm 0.15$ & $0.00 \pm 0.11$ & 0.716 \\
\hline$\vee$ & $5.54 \pm 0.23$ & $5.55 \pm 0.20$ & $-0.01 \pm 0.08$ & 0.430 \\
\hline \multicolumn{5}{|c|}{ Interpeak latency (ms) } \\
\hline$|-|||$ & $2.19 \pm 0.14$ & $2.18 \pm 0.15$ & $0.11 \pm 0.10$ & 0.499 \\
\hline $\mathrm{III}-\mathrm{V}$ & $1.91 \pm 0.18$ & $1.91 \pm 0.15$ & $0.00 \pm 0.12$ & 0.808 \\
\hline $\mathrm{I}-\mathrm{V}$ & $4.11 \pm 0.22$ & $4.10 \pm 0.21$ & $0.00 \pm 0.11$ & 0.700 \\
\hline \multicolumn{5}{|c|}{ Amplitude difference (peak to trough) $(\mu \mathrm{V})$} \\
\hline I & $0.28 \pm 0.12$ & $0.26 \pm 0.16$ & $0.02 \pm 0.15$ & 0.326 \\
\hline III & $0.34 \pm 0.13$ & $0.30 \pm 0.13$ & $0.04 \pm 0.11$ & 0.018 \\
\hline V & $0.55 \pm 0.20$ & $0.47 \pm 0.16$ & $0.08 \pm 0.16$ & 0.001 \\
\hline III/I & $1.49 \pm 1.22$ & $1.58 \pm 1.28$ & $-0.08 \pm 1.11$ & 0.620 \\
\hline $\mathrm{V} / \mathrm{I}$ & $2.41 \pm 1.83$ & $2.82 \pm 3.06$ & $-0.41 \pm 3.06$ & 0.385 \\
\hline
\end{tabular}

Table 5. Auditory brainstem response parameters in left tinnitus patient $(n=58)$

\begin{tabular}{|c|c|c|c|c|}
\hline & Ipsilesional & Contralesional & Difference & $p$-value \\
\hline \multicolumn{5}{|c|}{ Latency difference (ms) } \\
\hline I & $1.45 \pm 0.10$ & $1.41 \pm 0.11$ & $0.03 \pm 0.09$ & 0.003 \\
\hline III & $3.68 \pm 0.20$ & $3.58 \pm 0.16$ & $0.09 \pm 0.15$ & 0.000 \\
\hline$\vee$ & $5.55 \pm 0.27$ & $5.55 \pm 0.28$ & $0.03 \pm 0.08$ & 0.006 \\
\hline \multicolumn{5}{|c|}{ Interpeak latency (ms) } \\
\hline$|-|||$ & $2.23 \pm 0.19$ & $2.17 \pm 0.17$ & $0.05 \pm 0.17$ & 0.015 \\
\hline$I I I-V$ & $1.87 \pm 0.19$ & $1.93 \pm 0.55$ & $-0.06 \pm 0.13$ & 0.001 \\
\hline $\mathrm{I}-\mathrm{V}$ & $4.10 \pm 0.27$ & $4.11 \pm 0.27$ & $0.00 \pm 0.11$ & 0.646 \\
\hline \multicolumn{5}{|c|}{ Amplitude difference (peak to trough) $(\mu \mathrm{V})$} \\
\hline I & $0.24 \pm 0.13$ & $0.26 \pm 0.14$ & $-0.02 \pm 0.12$ & 0.139 \\
\hline III & $0.25 \pm 0.11$ & $0.32 \pm 0.13$ & $-0.07 \pm 0.10$ & 0.000 \\
\hline$\vee$ & $0.44 \pm 0.13$ & $0.49 \pm 0.17$ & $-0.04 \pm 0.16$ & 0.057 \\
\hline III/I & $1.41 \pm 1.15$ & $1.72 \pm 1.81$ & $-0.30 \pm 1.69$ & 0.172 \\
\hline$V / I$ & $3.22 \pm 5.49$ & $2.73 \pm 3.02$ & $0.48 \pm 3.57$ & 0.304 \\
\hline
\end{tabular}

\section{우측 이명 환자군의 청성뇌간반응 측정지표의 비교}

우측 이명 환자를 대상으로 병변 측과 건 측의 청성뇌간반 응을 비교하였을 때, 통계적으로 유의한 잠복기 지연 또는 단 축은 관찰되지 않았다(Table 4). 진폭의 경우 건 측에 비해 병변 측의 III파, V파의 진폭이 통계적으로 유의하게 증가되 었다(III파; $p=0.018, \mathrm{~V}$ 파; $p=0.001$ ). 하지만 III파/I파 진폭비 와 V파/I파의 진폭비는 통계적으로 유의하게 증가하지 않았 다(Table 4).

\section{좌측 이명 환자군의 청성뇌간반응 측정지표의 비교}

우측 이명 환자를 대상으로 병변 측과 건 측의 청성뇌간반 응을 비교하였을 때, 통계적으로 건 측에 비해 병변 측의 잠 복기 지연이 관찰되었으며, 이는 I파, III파, V파 모두에서 관
Table 6. Auditory brainstem response parameters in normal hearing tinnitus patient $(n=27)$

\begin{tabular}{ccccc}
\hline & Ipsilesional & Contralesional & Difference & p-value \\
\hline \multicolumn{2}{c}{ Latency difference (ms) } \\
I & $1.38 \pm 0.10$ & $1.38 \pm 0.09$ & $0.00 \pm 0.08$ & 0.813 \\
III & $3.60 \pm 0.15$ & $3.55 \pm 0.14$ & $0.04 \pm 0.09$ & 0.015 \\
V & $5.45 \pm 0.21$ & $5.44 \pm 0.19$ & $0.01 \pm 0.09$ & 0.300 \\
Interpeak latency (ms) & & & \\
I-III & $2.22 \pm 0.12$ & $2.17 \pm 0.14$ & $0.04 \pm 0.09$ & 0.023 \\
III-V & $1.85 \pm 0.15$ & $1.88 \pm 0.13$ & $-0.03 \pm 0.10$ & 0.134 \\
I-V & $4.07 \pm 0.22$ & $4.05 \pm 0.19$ & $0.01 \pm 0.10$ & 0.471 \\
Amplitude difference (peak to trough) & $(\mu \mathrm{V})$ & \\
I & $0.34 \pm 0.12$ & $0.37 \pm 0.16$ & $-0.02 \pm 0.15$ & 0.358 \\
III & $0.35 \pm 0.13$ & $0.37 \pm 0.14$ & $-0.02 \pm 0.14$ & 0.328 \\
V & $0.55 \pm 0.17$ & $0.52 \pm 0.17$ & $0.02 \pm 0.17$ & 0.404 \\
III/I & $1.13 \pm 0.56$ & $1.15 \pm 0.63$ & $-0.02 \pm 0.86$ & 0.865 \\
V/I & $1.86 \pm 1.10$ & $1.77 \pm 1.23$ & $0.09 \pm 1.52$ & 0.751 \\
\hline
\end{tabular}

찰되었다(I파; $p=0.003$, III파; $p<0.000, \mathrm{~V}$ 파; $p=0.006$ )(Table 5). I-V파 간 잠복기는 통계적으로 유의한 차이는 관찰되지 않았으나, 병변 측에서 I-III파 간 잠복기의 지연이 관찰되고 $(p=0.015), \mathrm{III}-\mathrm{V}$ 파 간 잠복기의 단축이 관찰되어 $(p=0.001) \mathrm{I}$ 파 와 $\mathrm{V}$ 파의 잠복기의 지연에 기인하는 것으로 생각된다(Table 5). 진폭의 경우, 건 측에 비해 병변 측 III파의 진폭이 유의하게 감소되었으나 $(p<0.000)$, III파/I파 진폭비는 통계적으로 유의 한 차이가 나타나지 않았다(Table 5).

\section{정상청력 이명 환자군의 청성뇌간반응 측정지표의 비교}

정상청력을 가진 이명 환자를 대상으로 병변 측과 건 측의 청성뇌간반응을 비교하였을 때, 통계적으로 건 측에 비해 병 변 측에서 III파의 잠복기 지연이 관찰되었다 $(p=0.015)$ (Table 6). 또한 I-III파 간 잠복기에서도 병변 측의 유의한 지연이 관 찰되었다 $(p=0.023)$. 그 외에 $\mathrm{I}$ 파와 $\mathrm{V}$ 파의 잠복기 또한 진폭에서 는 통계적으로 유의한 차이는 없었다(Table 6).

\section{고 찰}

본 연구는 일측성 이명 환자를 대상으로 청성뇌간반응을 비교한 것으로, 병변 측과 건 측을 비교했을 때, 병변 측 III 파의 잠복기 지연 및 진폭 감소를 관찰하였다(Table 3). 이는 $250 \mathrm{~Hz}$ 부터 $8 \mathrm{kHz}$ 의 순음청력검사상 기도청력 역치가 모두 $20 \mathrm{~dB}$ 이하인 정상청력을 지닌 이명 환자에서도 비슷한 소견 이었으며, 병변 측 III파의 진폭은 건 측과 유의한 차이가 없 었으나, 병변 측 III파의 잠복기 지연이 유의하게 관찰되었다 (Table 6). 이명 환자에게서 청성뇌간반응 결과의 이상 여부는 이전부터 많이 언급되어 왔던 부분이나, 이상 소견이 있는지, 
정확히 어떠한 요소가 이상을 보이는지는 이견이 많다. 정상 청력을 보이는 17 명의 주관적 이명 환자에게서 청상뇌간반응 의 이상 소견이 없었다는 연구에서부터, ${ }^{13)} 1 \sim 4 \mathrm{kHz}$ 의 청력을 정상인과 매칭하여 비교하였을 때 여성 이명 환자에게서 I파 의 잠복기 지연을 보고한 연구, ${ }^{14)}$ 순음청력검사상 $500 \mathrm{~Hz} 8$ $\mathrm{kHz}$ 까지의 주파수에서 $25 \mathrm{~dB}$ 이상의 청력 역치를 지닌 이명 환자와 정상인을 비교하여 이명 환자에게서 I파, III파, V파 의 지연을 보고한 연구, ${ }^{15)}$ 이명을 보이는 남성 환자를 정상 남 성과 비교하였을 때, I파의 진폭 감소, $\mathrm{V}$ 파의 진폭 증가 및 $\mathrm{V}$ 파/I파의 진폭비의 증가를 보고한 연구 ${ }^{2}$ 정상청력을 보이는 이 명 환자에게서 I파의 진폭 감소를 보고한 연구 ${ }^{16}$ 등 다양하다.

이명의 발생기전에 대해 여러 논의가 있어 왔다. 청각신경 (auditory nerve)에 문제가 발생하여 이로부터 이명이 초래될 가능성뿐만 아니라, 그보다 상위의 기관에서 이명이 초래될 가능성 또한 제기되었다. 신경차단술에도 호전되지 않는 이명 이 존재한다는 점ㄱㄱㄱㅘ functional MRI상 이명 환자의 inferior colliculi의 반응이 증가했다는 연구 ${ }^{18}$ 가 이를 뒷받침한다. 본 연구에서 청신경종양을 감별하기 위해 $\mathrm{V}$ 파 이간 잠복기 차이 (interaural wave V latency difference)가 $0.2 \mathrm{~ms}$ 를 초과하 는 경우 제외하였기 때문에 병 측 $\mathrm{V}$ 파의 잠복기 지연은 관찰 되지 않았으나, 전체 이명 환자군과 정상청력을 가진 이명 환 자군에서 병 측 III파의 잠복기 지연이 관찰된 점을 미루어 볼 때, 청각신경보다 상위의 기관에서 이명의 병태생리에 관여 함을 알 수 있다.

흥미롭게도 본 연구에서 이명의 방향에 따라 우측 이명 환 자군과 좌측 이명 환자군으로 나누어 분석하였을 때, 청성뇌 간반응 소견이 다르게 나타났다. 우측 이명 환자의 경우 병 측의 III파와 V파의 진폭이 건 측에 비해 유의하게 증가하였 고(Table 4), 좌측 이명 환자의 경우 병 측 III파의 진폭은 건 측에 비해 오히려 감소되었고, 주로 I파와 III파의 잠복기 지연 이 관찰되었다(Table 5). 사람의 청각 경로(auditory pathway) 는 양측 모두에 존재하고, 동 측 및 반대 측으로 교차하게 되 나, 기능상으로는 좌우가 비대칭이며, 대개의 경우 좌측 대뇌 의 일차 청각 피질(primary auditory cortex)이 우세를 보이게 된다. 따라서, 본 연구에서 우측과 좌측 이명 환자의 청성뇌 간반응 소견이 상이했던 점을 고려했을 때, 우측과 좌측 이 명의 병태생리가 다를 수 있음을 시사할 수 있다. 다만 일측 성 이명 환자의 청성뇌간반응에 관해 다룬 기존 논문이 적어, 추후 후속연구를 통해 검증이 필요할 것이다.

우측 이명 환자에서 관찰된 병 측의 III파와 V파의 증가된 진폭 소견은 파형의 기원을 고려했을 때 뇌간 혹은 그 상위 기관의 과활성화와 관련 있을 것으로 생각할 수 있다. 이명 의 시작은 말초신경계에서 시작될 수 있으나, 이명의 지속적
인 발생에 있어 중추신경계의 신경활성이 중요하다는 의견이 받아들여지고 있고, ${ }^{19)}$ 저하된 말초신경계의 기능저하에 대해 중추신경계의 과활성화가 일어난다는 가설이 제기되고 있 다. ${ }^{20)}$ 좌측 이명 환자에서 관찰된 I파와 III파의 잠복기 지연 및 III파의 진폭 감소 소견은 말초 청각 경로(peripheral auditory pathway)에서 지연이 두드러진 것으로 판단된다. 예를 들어 청 각신경의 부분적 탈수초화(partial demyelination)가 존재한 다면 잠복기 지연으로 나타날 수 있고, 지연된 신호들의 합선 전송(ephaptic transmission)으로 인해 III파의 진폭 감소 및 이명이 발생될 수 있다. ${ }^{21)}$

본 연구에서 일측성 이명 환자를 대상으로 청성뇌간반응 을 비교하여, 중추신경계의 변화 소견을 확인하였고, 이명의 병태생리가 이명의 방향에 따라 다를 수 있음을 시사하였다. 하지만 뇌 자기공명영상을 시행하여 청신경종양을 감별하지 못하였고, 이명의 특성을 보정하지 않고 분석한 제한점이 있 다. 따라서 추후 이명의 방향에 따른 병태생리를 알아보기 위해 추가적인 연구가 필요할 것으로 생각된다.

\section{REFERENCES}

1) Park GY, Choi JE, Cho YS. Traumatic ossicular disruption with isolated fracture of the stapes suprastructure: comparison with incudostapedial joint dislocation. Acta Otolaryngol 2014;134(12):1225-30.

2) Gu JW, Herrmann BS, Levine RA, Melcher JR. Brainstem auditory evoked potentials suggest a role for the ventral cochlear nucleus in tinnitus. J Assoc Res Otolaryngol 2012;13(6):819-33.

3) Davis AC. The prevalence of hearing impairment and reported hearing disability among adults in Great Britain. Int J Epidemiol 1989;18(4): 911-7.

4) Joo YH, Han KD, Park KH. Association of hearing loss and tinnitus with health-related quality of life: the Korea National Health and Nutrition Examination Survey. PLoS One 2015;10(6):e0131247.

5) Kral A, Majernik V. On lateral inhibition in the auditory system. Gen Physiol Biophys 1996;15(2):109-27.

6) Brozoski TJ, Spires TJ, Bauer CA. Vigabatrin, a GABA transaminase inhibitor, reversibly eliminates tinnitus in an animal model. J Assoc Res Otolaryngol 2007;8(1):105-18.

7) Yoo SY, Kim TS, Moon IS, Park SN, Shin JE, Lee HK, et al. Current Trends in the Treatment of Subjective Tinnitus at University Hospitals in Korea. Korean J Otorhinolaryngol-Head Neck Surg 2013;56(5): 266-77.

8) Chang J, Kim TS, Nam EC, Moon IS, Park MK, Park SN, et al. Current trends in the assessment of patients with tinnitus and the proposal of tinnitus assessment in Korea. Korean J OtorhinolaryngolHead Neck Surg 2014;57(10):671-86.

9) Dehmel S, Eisinger D, Shore SE. Gap prepulse inhibition and auditory brainstem-evoked potentials as objective measures for tinnitus in guinea pigs. Front Syst Neurosci 2012;6:42.

10) Godey B, Morandi X, Beust L, Brassier G, Bourdinière J. Sensitivity of auditory brainstem response in acoustic neuroma screening. Acta Otolaryngol 1998;118(4):501-4.

11) Kim CS, Jun SH, Kim LS, Kim HK. Clinical study on auditory brainstem response. Korean J Otorhinolaryngol-Head Neck Surg 1985;28(3):279-83.

12) Moon IH, Lee KS, Han YH, Sung JY, Choi IS, Park JY, et al. Tinnitus masking effects using various kinds of sound and music. Korean J 
Otolaryngol-Head Neck Surg 1999;42(2):173-83.

13) Barnea G, Attias J, Gold S, Shahar A. Tinnitus with normal hearing sensitivity: extended high-frequency audiometry and auditorynerve brain-stem-evoked responses. Audiology 1990;29(1):36-45.

14) Ikner CL, Hassen AH. The effect of tinnitus on ABR latencies. Ear Hear 1990;11(1):16-20.

15) Kehrle HM, Granjeiro RC, Sampaio AL, Bezerra R, Almeida VF, Oliveira CA. Comparison of auditory brainstem response results in normal-hearing patients with and without tinnitus. Arch Otolaryngol Head Neck Surg 2008;134(6):647-51.

16) Schaette R, McAlpine D. Tinnitus with a normal audiogram: physiological evidence for hidden hearing loss and computational model. J Neurosci 2011;31(38):13452-7.
17) Brackmann DE, Barrs DM. Assessing recovery of facial function following acoustic neuroma surgery. Otolaryngol Head Neck Surg 1984;92(1):88-93.

18) Lanting CP1, De Kleine E, Bartels H, Van Dijk P. Functional imaging of unilateral tinnitus using fMRI. Acta Otolaryngol 2008;128(4): 415-21.

19) Jung DJ, Lee KY. Mechanism of tinnitus generation. Korean J Otorhinolaryngol-Head Neck Surg 2014;57(6):357-63.

20) Noreña AJ. An integrative model of tinnitus based on a central gain controlling neural sensitivity. Neurosci Biobehav Rev 2011;35(5):1089109.

21) Lenarz T, Schreiner C, Snyder RL, Ernst A. Neural mechanisms of tinnitus. Eur Arch Otorhinolaryngol 1993;249(8):441-6. 